\title{
Job shop scheduling considering material handling process
}

\author{
Eka K.A. Pakpahan ${ }^{1, *}$, Sonna Kristina ${ }^{1}$, Ari Setiawan ${ }^{1}$ and Evelin Merlians ${ }^{1}$ \\ ${ }^{1}$ Industrial Engineering, Harapan Bangsa Institute of Technology, 40132 Bandung, Indonesia
}

\begin{abstract}
This paper discussed job shop scheduling considering material handling process. This process is a very important aspect on a flexible manufacturing system, where raw material or semifinished goods are delivered from one processing point unto another by utilizing automated material handling equipment, functioned as shared resources. The starting time of each process is affected by the ability of the material handling equipment to conduct timely delivery from one point to another, therefore considering this process unto scheduling is important to enable planner to get precise estimation of the process makespan. We take the case where the flexible manufacturing system is consisted of four identical machines; each has the capability of processing various jobs due to the various cutting tools installed on their tools magazine. Jobs are dispatched based on longest processing time rule and then allocated to machine which has minimum load. Being a shared resource, material handling equipment has pick-up and delivery priority rule when handling multiple requests. The two most common rules are longest waiting and closest entity. This paper will analyzed the impact of each rule to the process makespan and material handling equipment utilization. Simulation model were built using Promodel to give decision maker better visualization of the system under consideration.
\end{abstract}

\section{Introduction}

The pursuit of achieving flexibility and timeliness on manufacturing system has brought manufacturer in to the choice of adopting flexible manufacturing system (FMS). An FMS is generally consisted of machines, storage, and material handling system which is integrated and controlled by a computer center [1]. The computer center is responsible for creating job dispatch list which then automatically dictate the material handling system on conducting material pick-up and delivery from one processing point unto another. The system will then operate without operator attendance for a specified time interval.

\footnotetext{
Corresponding author: eka@ithb.ac.id
} 
We consider here a specific FMS where four identical machines, pallet stocker and stacker crane (as material handling system) are integrated by computer center. The system will process jobs which has multiple stages. The stages are sequence dependent, meaning stage two can only begin after stage one is finished. At the start of the production shift, operator will check on the list of jobs to be processed and then create dispatch list on the computer center. Jobs will then be setup on the loading/unloading area. The stacker crane, having role as shared resource, is responsible for delivering parts from loading/unloading area unto machines, back to loading/unloading area to be setup for the second stage, unto machine and then to the pallet stocker as the storage area. The stacker crane can only move one part at a particular time. The system is to be operated unmanned for 24 hours, so the aim for this system is to have all the parts processed (makespan) less than 24 hours.

There are several research conducted to deal with the specified system above. Research by [2] starts by applying genetic algorithm to generate job dispatch list, the calculation were done manually thus inefficient in terms of computation time. Improvements were done by [3], [4] and [5] by adopting three different heuristic and meta-heuristic approaches, but they all excludes material handling process by assuming that stacker crane is always available and transportation time equals to zero. This assumption cannot always be true. Being a shared resource there are possibilities that stacker crane is required by multiple jobs, it then can only select one job to be picked up and delivered at a particular time. This will leads to the delay of another job to be processed. Without taking this phenomenon into account the makespan will be underestimated.

This paper aims to model the transportation process conducted by stacker crane given that dispatch list is already been determined. When there are multiple jobs to be picked up, several rules can be applied, such as random [6], shortest travels distance first [7], and longest waiting rule [8]. We will apply these rules and compared their performance in terms of makespan and stacker crane utilization.

We will present the paper in five sections. Section 1 presents the introduction and motivation of the research, section 2 presents the research methods, section 3 presents the system description and simulation modeling, section 4 presents the simulation result and analysis and section 5 presents the research conclusion.

\section{Methods}

Many studies show that simulation is found to be an effective tool in design and operation of an FMS [8]. Simulation can benefit us when we want to study the impact of a certain control policy without disturbing the real system. Depend on the simulation software; it can also give us better visualization about the way the system works. Taking these into consideration, we took simulation as our research approach and Promodel as our simulation platform.

\section{System Modelling}

\subsection{System Description}

Consider an FMS work center consisted of one loading/unloading area, four identical machines with incoming and outgoing buffer area in front of each machine, and pallet stocker with the capacity of 60 pallets, all integrated by a computer center. The pallet stocker was assigned evenly to serve each machine (15 pallet stocker for each). Whenever a machine is selected as processing destination but currently unavailable, job would be queued up on the incoming buffer and the pallet stocker dedicated for that particular machine. (See the layout on Figure 1). 


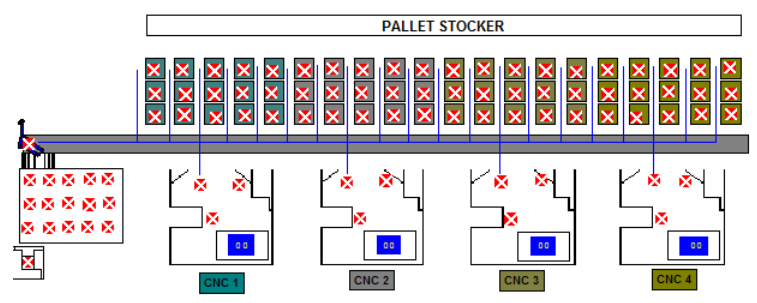

Fig. 1. FMS Work Center Layout

There are 15 jobs each having 1 or 2 process stages, each stage is consisted of several operations. The operations on a particular stage have to be processed in one machine to avoid damage due to frequent handling, so we do not modeled the detail of the operation sequence here. The processing requirement were saved and identified by the entity attribute (named part number), see the details of part number processing time on Table 1.

\subsection{Simulation Model Building}

We create dispatch list by applying longest processing time (LPT) rule. The selection of this rule is based on the aim to minimize process makespan [9]. The steps of simulation were given below:

Step 1 Initialization, read part number processing time, set machines load as zero.

Step 2 Apply LPT rule to sort part number based on its first stage processing time.

Step 3 Read from the part number sorted list, starting from the first sequence on the list; determine machines with the least load and select the particular machine (defined by the machine number) as the job processor. Update the load for the chosen machine by adding part processing time to its current load.

Table 1. Part Number Processing Time

\begin{tabular}{|c|c|r|}
\hline $\begin{array}{c}\text { Part } \\
\text { Number }\end{array}$ & Stage & $\begin{array}{c}\text { Processing } \\
\text { Time } \\
\text { (minutes) }\end{array}$ \\
\hline 1 & 1 & 80 \\
\hline \multirow{2}{*}{2} & 1 & 240 \\
\cline { 2 - 3 } & 2 & 240 \\
\hline \multirow{2}{*}{3} & 1 & 280 \\
\cline { 2 - 3 } & 2 & 280 \\
\hline \multirow{2}{*}{4} & 1 & 240 \\
\cline { 2 - 3 } & 2 & 120 \\
\hline 5 & 1 & 90 \\
\hline 6 & 1 & 100 \\
\hline \multirow{2}{*}{7} & 1 & 240 \\
\cline { 2 - 3 } & 2 & 200 \\
\hline \multirow{2}{*}{8} & 1 & 240 \\
\cline { 2 - 3 } & 2 & 120 \\
\hline \multirow{2}{*}{9} & 1 & 280 \\
\cline { 2 - 3 } & 2 & 280 \\
\hline \multirow{2}{*}{10} & 1 & 240 \\
\cline { 2 - 3 } & 2 & 240 \\
\hline
\end{tabular}




\begin{tabular}{|l|r|r|}
\multirow{2}{*}{11} & 1 & 160 \\
\cline { 2 - 3 } & 2 & 240 \\
\hline \multirow{2}{*}{12} & 1 & 320 \\
\cline { 2 - 3 } & 2 & 200 \\
\hline \multirow{2}{*}{13} & 1 & 240 \\
\cline { 2 - 3 } & 2 & 200 \\
\hline 14 & 1 & 90 \\
\hline 15 & 1 & 80 \\
\hline
\end{tabular}

Step 4 Based on the machine number selected on step 3, check on the current availability of the machine (whether it is currently processing another job). If it is available, select the machine as destination point and go to step 7, else go to step 5.

Step 5 Based on the machine number selected on step 3, check on the availability of incoming buffer at the machine (whether it is occupied by another job). If it is available, select the incoming buffer of the machine as destination point and go to step 7, else go to step 6 .

Step 6 Based on the machine number selected on step 3, check on the availability of its dedicated pallet stocker (whether it is occupied by another job). If it is available select the pallet stocker of the machine as destination point and go to step 7, else wait until one of the condition mentioned on step 4, 5 and 6 are met.

Step 7 Send pick up request to stacker crane.

Step 8 Stacker crane will create request list, and answer the request based on its priority rule. Starting from the first job on the list, stacker crane would read the destination point and deliver jobs accordingly. Any requests conducted during the delivery process were recorded on the stacker crane request list. After delivering jobs, stacker crane will pause and read its request list to determine the next pick up location. If there are no other request it will then parked on the last delivery destination.

Step 9 For part at the destination machine, read the data from table 1 and begin processing time. Update machine availability status from available to unavailable.

Step 10 For part at the machine. At the end of processing time, entity is routed to machine outgoing buffer. Update machine availability status from unavailable to available.

Step 11 For part at the outgoing buffer, read the data and determine whether there is stage 2 processing or not. If yes, loading/unloading will be selected as destination point, else pallet stocker will be selected as destination point. Go to Step 7.

Step 12 Checks whether all jobs has been processed, if yes, go to step 13, else, go back to step 3.

Step 13 Calculate the makespan of the process.

The speed of the stacker crane is defined to be 30 meter/minute, and the travel distance from one point to another is specified as in Table 2, 3 and 4. 
Table 2. Material Handling Bi-Directional Distance from Loading/unloading Area to Machine and Raw Material Pallet Stocker

\begin{tabular}{|l|r|r|}
\hline Destination & $\begin{array}{c}\text { Horizontal } \\
\text { Distance }\end{array}$ & $\begin{array}{r}\text { Vertical } \\
\text { Distance }\end{array}$ \\
\hline PS_M1_1 & 3.10 & 0 \\
\hline PS_M1_2 & 3.86 & 0 \\
\hline PS_M1_3 & 4.62 & 0 \\
\hline Machine 1 & 4.62 & 1.06 \\
\hline PS_M1_4 & 5.38 & 0 \\
\hline PS_M1_5 & 6.14 & 0 \\
\hline PS_M2_1 & 6.90 & 0 \\
\hline PS_M2_2 & 7.66 & 0 \\
\hline PS_M2_3 & 8.42 & 0 \\
\hline Machine 2 & 8.42 & 1.06 \\
\hline PS_M2_4 & 9.18 & 0 \\
\hline PS_M2_5 & 9.94 & 0 \\
\hline PS_M3_1 & 10.70 & 0 \\
\hline PS_M3_2 & 11.46 & 0 \\
\hline PS_M3_3 & 12.22 & 0 \\
\hline Machine 3 & 12.22 & 1.06 \\
\hline PS_M3_4 & 12.98 & 0 \\
\hline PS_M3_5 & 13.74 & 0 \\
\hline PS_M4_1 & 14.50 & 0 \\
\hline PS_M4_2 & 15.26 & 0 \\
\hline PS_M4_3 & 16.02 & 0 \\
\hline Machine 4 & 16.02 & 1.06 \\
\hline PS_M4_4 & 16.78 & 0 \\
\hline PS_M4_5 & 17.54 & 0 \\
\hline
\end{tabular}

Table 3. Material Handling Bi-Directional Distance from Loading/unloading Area to Machine and Work in Progress Pallet Stocker

\begin{tabular}{|l|r|r|}
\hline Destination & $\begin{array}{c}\text { Horizontal } \\
\text { Distance }\end{array}$ & $\begin{array}{r}\text { Vertical } \\
\text { Distance }\end{array}$ \\
\hline WIP_M1_1 & 3.10 & 1.06 \\
\hline WIP_M1_2 & 3.86 & 1.06 \\
\hline WIP_M1_3 & 4.62 & 1.06 \\
\hline WIP_M1_4 & 5.38 & 1.06 \\
\hline WIP_M1_5 & 6.14 & 1.06 \\
\hline WIP_M2_1 & 6.90 & 1.06 \\
\hline WIP_M2_2 & 7.66 & 1.06 \\
\hline WIP_M2_3 & 8.42 & 1.06 \\
\hline WIP_M2_4 & 9.18 & 1.06 \\
\hline WIP_M2_5 & 9.94 & 1.06 \\
\hline WIP_M3_1 & 10.70 & 1.06 \\
\hline WIP_M3_2 & 11.46 & 1.06 \\
\hline WIP_M3_3 & 12.22 & 1.06 \\
\hline
\end{tabular}




\begin{tabular}{|c|c|c|} 
WIP_M3_4 & 12.98 & 1.06 \\
\hline WIP_M3_5 & 13.74 & 1.06 \\
\hline WIP_M4_1 & 14.50 & 1.06 \\
\hline WIP_M4_2 & 15.26 & 1.06 \\
\hline WIP_M4_3 & 16.02 & 1.06 \\
\hline WIP_M4_4 & 16.78 & 1.06 \\
\hline WIP_M4_5 & 17.54 & 1.06 \\
\hline
\end{tabular}

Table 4. Material Handling Bi-Directional Distance from Loading/unloading Area to Machine and Finished Product Pallet Stocker

\begin{tabular}{|l|r|r|}
\hline Destination & $\begin{array}{c}\text { Horizontal } \\
\text { Distance }\end{array}$ & $\begin{array}{c}\text { Vertical } \\
\text { Distance }\end{array}$ \\
\hline WIP_M1_1 & 3.10 & 2.12 \\
\hline WIP_M1_2 & 3.86 & 2.12 \\
\hline WIP_M1_3 & 4.62 & 2.12 \\
\hline WIP_M1_4 & 5.38 & 2.12 \\
\hline WIP_M1_5 & 6.14 & 2.12 \\
\hline WIP_M2_1 & 6.90 & 2.12 \\
\hline WIP_M2_2 & 7.66 & 2.12 \\
\hline WIP_M2_3 & 8.42 & 2.12 \\
\hline WIP_M2_4 & 9.18 & 2.12 \\
\hline WIP_M2_5 & 9.94 & 2.12 \\
\hline WIP_M3_1 & 10.70 & 2.12 \\
\hline WIP_M3_2 & 11.46 & 2.12 \\
\hline WIP_M3_3 & 12.22 & 2.12 \\
\hline WIP_M3_4 & 12.98 & 2.12 \\
\hline WIP_M3_5 & 13.74 & 2.12 \\
\hline WIP_M4_1 & 14.50 & 2.12 \\
\hline WIP_M4_2 & 15.26 & 2.12 \\
\hline WIP_M4_3 & 16.02 & 2.12 \\
\hline WIP_M4_4 & 16.78 & 2.12 \\
\hline WIP_M4_5 & 17.54 & 2.12 \\
\hline
\end{tabular}

\subsection{Simulation Model Verification}

Verification was done by using tracing and debugging function embedded on Promodel (10). The aim is to ensure the simulation model operates as intended. The example of tracing output is given on Figure 2. Overall tracing shows well verified output. 


\begin{tabular}{|c|c|c|}
\hline \multicolumn{2}{|l|}{ (1) TRACE } & $x$ \\
\hline 00:31:41.80 & For Part at CNC3: & A \\
\hline 00:31:41.80 & Umur CT $3[3,1]=90$ [old value $=120$ ] & \\
\hline 00:31:41.80 & Frees $\mathrm{CT}^{-} 3$ 3.1. & \\
\hline 00:31:41.80 & Obtains $\overline{\mathrm{CT}} \overline{3} \quad 4.1$. & \\
\hline 00:31:41.80 & Wait $40 \mathrm{Min} \overline{0} .00$ Sec. & \\
\hline $00: 31: 41.80$ & CT 33.1 starts work search. & \\
\hline 00:31:41.80 & No more work, wait for the next task. & \\
\hline $00: 37: 47.19$ & For Part at CNC4: & \\
\hline 00:37:47.19 & Umur_CT_4[1,1] $=85$ [old value $=120$ ] & \\
\hline $00: 37: 47.19$ & Frees CT_4_1.1. & \\
\hline 00:37:47.19 & Obtains $\overline{\mathrm{CT}} \overline{4} 2.1$. & $\square$ \\
\hline 00:37:47.19 & Wait $40 \mathrm{Min} \overline{0} .00$ Sec. & - \\
\hline
\end{tabular}

Fig. 2. Example of Tracing Output on Promodel

\section{Results and Discussion}

We build two scenarios. Each scenario differs on the stacker crane pick-up and delivery priority rule (see step 8 of the simulation). The first is longest waiting rule; that is stacker crane will give higher priority to pick up part number which has waited the longest. The second scenario is closest entity rule; that is stacker crane will give higher priority to pick up part number which has closest distance to the stacker crane current position. The simulation result for both scenarios is given on Table 5 and 6 . We also give scenario 0 (simulation without considering material handling process) as reference point for comparison.

Table 5. Makespan and Machine Utility for each Scenarios

\begin{tabular}{|c|c|c|c|c|c|}
\hline \multirow{2}{*}{ Scenario } & \multirow{2}{*}{$\begin{array}{c}\text { Makespan } \\
\text { (minutes) }\end{array}$} & \multicolumn{4}{|c|}{ Machine Utility (\%) } \\
\cline { 3 - 6 } & 1320 & 94.70 & 87.88 & 99.24 & 100.00 \\
\hline 0 & 1323 & 94.47 & 87.67 & 99.01 & 99.76 \\
\hline 1 & 1323 & 94.47 & 87.67 & 99.01 & 99.76 \\
\hline 2 & &
\end{tabular}

Table 6. Stacker Crane Utility for each Scenarios

\begin{tabular}{|c|r|r|r|}
\hline \multirow{2}{*}{ Scenario } & \multicolumn{3}{|c|}{ Stacker Crane Utility (\%) } \\
\cline { 2 - 4 } & Pickup & Delivery & \multicolumn{1}{c|}{ Total } \\
\hline 0 & N/A & N/A & N/A \\
\hline 1 & 1.4 & 1.6 & 3.00 \\
\hline 2 & 1.13 & 1.6 & 2.73 \\
\hline
\end{tabular}

We can see few highlights from the simulation result. First, by taking transportation process into consideration the makespan is lengthened for 23 minutes $(1.75 \%$ from the reference point). This value was not too significant due to the short distance of the material movement and the high speed of the stacker crane. Second, machine utility is lowered by $0.23 \%$ on average when we considered transportation process; this is because at some point of time, machine has to wait for part delivery. Third, there is no makespan difference between scenario 2 and 3, either longest waiting rule or closest entity rule had any effect to the makespan value. By observing the simulation process, we conclude that the material handling process only delay the starting time of the first jobs at each machine, after that there were no other cases found along the simulation where machine has to wait for stacker 
crane to deliver part to be processed. This is once again because the short distance of the material movement and the high speed of the stacker crane. Fourth, stacker crane utility differs on scenario 2 and 3 . The stacker crane total utility is found by summing the percentage time used for pickup and for delivery. We see that closest entity rule would decrease the percentage time used for pickup and therefore decrease the total utility for the stacker crane.

\section{Conclusions}

We have built simulation model for an FMS by considering material handling process. This research brought two levels of benefit, on the operational level as well as on strategic level. On the operational level, for the case described earlier, by knowing that the makespan is still within the 24 hours limit, the scheduler can safely execute the production plan. Using the same simulation model, they can also simulate various other cases of production plan and see its feasibility. On strategic level, one can consider changing the FMS cell design. From the simulation we see that the stacker crane utility is still very low. If there are plan to add machines to the shop floor, the current stacker crane can be further utilized.

This research is fully funded by the Ministry of Research, Technology and Higher Education of the Republic of Indonesia under the scheme of "Penelitian Dosen Pemula" Year of 2018, contract number 0918/K4/KM/2018.

\section{References}

1. A. Setiawan, Asia Pacific Industrial Engineering \& Management Systems Conference (2015).

2. A. Setiawan, Susan and E. Pakpahan, Jurnal Telematika Institut Teknologi Harapan Bangsa 9 (2014)

3. T. Surya, Laporan Tugas Akhir Teknik Industri Institut Teknologi Harapan Bangsa (2016)

4. K, Wahyudi, Laporan Tugas Akhir Teknik Industri Institut Teknologi Harapan Bangsa (2016)

5. A. Chandra, Laporan Tugas Akhir Teknik Industri, Institut Teknologi Harapan Bangsa (2016)

6. T. Sitepu, A. Setiawan and T. Marshall, Jurnal Petra Surabaya (under review) (2017)

7. T. Aized, K. Takahashi, I. Hagiwara, POMS 18th Annual Conference, Dallas, Texas, U.S.A., (2007).

8. B.S.P. Redy, C.S.P. Rao, Int. Journal Simul Model 10, 2 78-90 (2011)

9. A. Kuruvilla, G. Paletta, 6(1), 19-29, January-March (2015)

10. C. Harrell, B.K. Ghosh, and R. Bowden, McGraw-Hill (2000) 